\title{
Bilingual physical education: the effects of CLIL on physical activity levels
}

\section{Celina Salvador-García, Oscar Chiva-Bartoll \& Carlos Capella-Peris}

To cite this article: Celina Salvador-García, Oscar Chiva-Bartoll \& Carlos Capella-Peris (2019): Bilingual physical education: the effects of CLIL on physical activity levels, International Journal of Bilingual Education and Bilingualism, DOI: 10.1080/13670050.2019.1639131

To link to this article: https://doi.org/10.1080/13670050.2019.1639131

\section{曲 Published online: 12 Jul 2019.}

Submit your article to this journal $\pi$

View Crossmark data \lceil 


\title{
Bilingual physical education: the effects of CLIL on physical activity levels
}

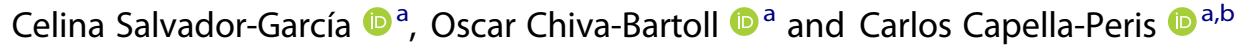

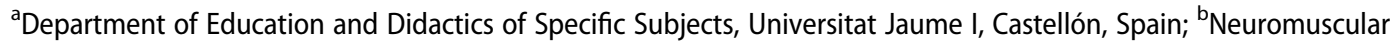 \\ Symptoms Unit, Tissue Injury Branch, National Institute of Nursing Research, National Institutes of Health, Rockville, \\ MD, USA
}

\begin{abstract}
Physical education (PE) is often the subject chosen for applying multilingual initiatives based on content and language integrated learning (CLIL). Some research literature (Lynott, F. J. 2008. "Integrating Other Subject Matter without Jeopardizing Physical Education Goals: The Content Linkage Approach." Strategies 22 (1): 10-17; Merino, J. 2016. "Non-Linguistic Content in CLIL: Is Its Learning Diminished?" In CLIL Experiences in Secondary and Tertiary Education: In Search of Good Practices, edited by D. Lasagabaster, and A. Doiz, 17-43. Bern: Peter Lang) suggests that this subject could lose its essence if too much emphasis is placed on language learning, as it could lead to a reduction in moderate-vigorous physical activity (MVPA), which is directly related to healthy lifestyles. Given that PE needs to increase MVPA, while also allowing students to learn new languages, the purpose of this study is to analyse whether CLIL affects the levels of MVPA and, if so, to understand how and why. Through a mixed methodological approach based on a sequential explanatory design, data were collected and analysed in two consecutive phases: a quantitative one $(n=49)$ based on a quasi-experimental design in which mixed and factorial ANOVA were applied; and a qualitative one based on a subsequent analysis of interviews with 13 participants. The results show that levels of MVPA are higher in the experimental group (CLIL) due to the greater attention paid and the use of certain communicative teaching strategies.
\end{abstract}

\section{ARTICLE HISTORY}

Received 6 April 2019

Accepted 26 June 2019

\section{KEYWORDS}

Physical education; CLIL; moderate-vigorous physical activity; pedagogical approach; mixed methods

\section{Introduction}

In the past few decades a multilingual approach to education has been a priority in the European policy-making landscape (Marsh 2012). This might be connected to the globalisation process (Cenoz, Genesee, and Gorter 2014). For example, the priorities of ET2020 include improving the efficiency of one of the most widely used approaches for teaching languages, content and language integrated learning (CLIL) (Coyle, Hood, and Marsh 2010); Spain is one of the countries in which such initiatives have been most readily adopted (Coyle 2010; Merino and Lasagabaster 2018).

The implementation of CLIL has elicited a wide range of reactions, from demonisation to idealisation (Pérez-Cañado 2016). On the one hand, it has been claimed that language learning is prioritised while other subjects in the curriculum are undervalued. On the other hand, however, CLIL has been defended as a beneficial approach for language learning (Dalton-Puffer 2011; Merino and Lasagabaster 2018). Various studies have analysed the consequences of applying CLIL for motivation or improvements in students' social skills (Fernández-Río, Hortigüela Alcalá, and Pérez Pueyo 2017). 
In any case, proper use of CLIL inevitably involves a change in the teaching and learning process (Coyle 2015), which is why authors such as Cenoz, Genesee, and Gorter (2014) and Pérez-Cañado (2016) have pointed to the need to investigate, beyond the merely linguistic aspect, how subjects are affected when CLIL is applied.

Physical education (PE) is one of the subjects most commonly chosen for introducing CLIL (Baena, Gómez, and Granero 2017; Gruber 2015; Salvador, Chiva, and Isidori 2017; Zindler 2013), since it is argued that, due to its procedural nature, it offers numerous possibilities that favour language learning (Coral 2013). In addition, there is a growing body of research literature on teaching PE through CLIL focusing, among other topics, on students' motivation, the language used in the lessons, or teachers' perceptions (Baena, Gómez, and Granero 2017; Forey and Cheung 2019; Salvador and Chiva 2017). But despite this, there are still concerns about PE, like other subjects, losing its identity if too much emphasis is placed on language (Merino 2016). One of the most often repeated arguments is that the addition of the new language could reduce the content and function of PE (Martínez and García 2017), especially motor learning, since it involves spending a lot of time on physical practice (Coral 2013; Lynott 2008).

In particular, CLIL could compromise the time spent doing physical activity due to the need for more lengthy explanations (Chiva and Salvador 2016; Coral et al. 2017; Gómez and Jiménez 2012) and the fact that students must be encouraged to use all four linguistic skills (listening, speaking, reading and writing) (Coral 2013; Salvador and Chiva 2017). For example, the pilot study by Coral et al. (2017) analysed the amount of physical activity carried out in PE lessons with CLIL. The results, which were obtained through an observation tool, suggest that the percentage of time spent on motor activities is lower than that recommended by the educational authorities.

However, PE lessons are currently required to promote increased levels of moderate-vigorous physical activity (MVPA), as this is the type of intensity most directly associated with positive health effects (Martínez et al. 2012). According to the World Health Organization (WHO 2013), MVPA is the level of intensity that generates a physiological response in the body comparable to activities such as walking fast or cycling. Interestingly, for many young people PE lessons are the only chance they have to do a minimum amount of physical activity each week (Meyer et al. 2013). This subject is therefore crucial for promoting healthy lifestyles among young people (Martínez et al. 2012), especially girls (Murillo et al. 2014). A lack of activity is associated with the risk of heart disease, diabetes and cancer (US Department of Health and Human Services 2012). In fact, the specialised literature states that the time students spend on MVPA in PE lessons should actually be increased, as can be gathered from the review by Fairclough and Stratton (2005) or the metaanalysis by Hollis et al. (2017).

Therefore, due to the need to ensure healthy levels of MVPA and the concern that the amount of physical activity carried out in PE lessons could be affected (Coral et al. 2017; Martínez and García 2017), further studies are required to determine whether the levels of physical activity achieved through CLIL differ considerably from healthy levels of MVPA. In this research, we have chosen to use accelerometry, a technique for quantifying acceleration patterns based on high-frequency recordings, to test this as rigorously and accurately as possible, since the scientific literature describes it as one of the most reliable and objective ways of measuring physical activity (Murillo et al. 2014). Accelerometers have been found to be one of the most objective tools to measure the amount of physical activity (Calahorro et al. 2015), and they have been increasingly used to measure the physical activity of school children (Rowlands et al. 2014). To address the above concerns, the present study investigates if the use of CLIL affects the students' level of MVPA and which are the main reasons underlying the phenomenon.

\section{Method}

The study was carried out using a mixed method with a predominantly quantitative explanatory sequential design (Creswell et al. 2003). A quasi-experimental design was applied to the quantitative data, comparing the levels of MVPA of an experimental group (CLIL) with those of a control group 
(NON-CLIL). MVPA was measured by accelerometry. Then the teacher and students in the experimental group were interviewed in order to complement the quantitative results with the intention of interpreting them more thoroughly.

\section{Hypothesis}

The hypothesis of the quantitative study holds that the experimental group (CLIL) will obtain significantly lower MVPA values than those of the control group (NON-CLIL). It is also expected that MVPA will be greater for the boys than for the girls in each group.

\section{Research question}

The research question for the qualitative part of the study is: What are the underlying reasons for changes in the level of MVPA when CLIL is applied in PE?

\section{Research design}

From the quantitative perspective, a quasi-experimental design was applied based on non-equivalent natural groups to make an objective analysis of MVPA levels in PE lessons, which is one of the most common designs in educational research (Tejedor 2000). Two class groups were randomly selected, one of which had PE sessions using the CLIL approach and the other without CLIL. The same conditions were established in both groups for variables such as the school, level of education, PE teacher and curricular content. In the second phase, this design was complemented by a qualitative approach in order to answer the research question by addressing the perceptions, experiences and feelings expressed by the participants (Creswell et al. 2003).

\section{Participants}

The sample for the quantitative study consisted of 49 secondary school students born in 2003 . The experimental group (CLIL) consisted of 13 girls and 10 boys, while the control group (NON-CLIL) included 19 girls and 7 boys. First, it was ensured that the sample presented a statistically proportional distribution in terms of the gender variable between the groups $X^{2}(N=49)=1.05, p=.306$.

In the qualitative part an intentional sample was chosen, including the teacher and 12 students (Patton 2002). The reason for this type of sampling was to achieve quotas of participants who were representative of the class group in relation to criteria that the research team believed could condition their experience: (1) gender, (2) English marks for the last academic year and (3) PE marks for the last academic year. The sample comprised three representatives from each quadrant (Table 1).

\section{Procedure}

Each group had two 50-minute classes per week in the morning. The quantitative data were collected during a unit taught in January and in February 2017, while the interviews were carried out once the intervention had ended. Accelerometry data were taken in both groups. Each participant was assigned an accelerometer (a device that measures the acceleration of a body through high-frequency recordings in order to discriminate behavioural patterns of physical activity).

Table 1. Characteristics of the students interviewed.

\begin{tabular}{lccc}
+ & $N=3$ & $N=3$ \\
PE mark & $N=3$ & & $N=3$ \\
- & - & English mark & + \\
\hline
\end{tabular}


An external observer, who attended all the sessions to monitor application, recorded the start and finish times of each session. The measurements from the accelerometers were adjusted to the actual class time (Ferreira, Mota, and Duarte 2014), as there is always some time when the students are not engaged in the session's objectives, such as time to get to the gym, time to get ready, or time for a shower (McKenzie et al. 2000). Given that our study focused on comparing levels of MVPA, we decided only to include the actual class time of the sessions, as was also the case with Ferreira, Mota, and Duarte (2014), Harvey et al. (2016) and Kremer, Reichert, and Hallal (2011). The observer also completed the CLIL planning and observation checklist (Mehisto, Marsh, and Frigols 2008) to ensure the approach was being used properly.

The topic chosen was athletics, since it has already been used in previous studies on CLIL (Griva and Kasvikis 2015). It is one of the most common contents in PE (Ginciene and Matthiesen 2017), which facilitates the future reproducibility of the study. The teaching unit consisted of eight sessions, six of which were practical and two theoretical. No accelerometry measurements were taken during the theoretical sessions.

\section{Instruments}

Accelerometer: This instrument is considered one of the most reliable ways of measuring levels of physical activity and it does not interfere with PE sessions (Calahorro et al. 2015). Its use in research with children and teenagers has been validated for providing objective measurements of their levels of physical activity and, in fact, accelerometers are used in numerous research studies with minors (Calahorro et al. 2015; Hollis et al. 2017; Martínez et al. 2012). In this study, levels of physical activity were calculated using the GENEActiv Original triaxial accelerometer, worn on the left wrist.

Semi-structured interview: The teacher and twelve students from the experimental group were interviewed after the intervention, following a semi-structured format that made it possible to enquire about what happened in the sessions. Four students participated in individual interviews and the rest were interviewed as a group. It was thus possible for individual experiences to be complemented by a collective discourse, comparing and contrasting different perspectives and thus avoiding any distortion of the situation. Initially, general questions were asked before other more specific ones were gradually introduced in order to reconstruct the interviewees' subjective theories without them being influenced by the researcher (Flick 2009).

\section{Analysis}

With regard to the quantitative analysis, the data recorded by the accelerometers were exported into the statistical package SPSS-24. A mixed ANOVA was used to analyse the effect of the group variable on MVPA time. Then the impact that the gender variable had on the level of MVPA was verified by applying a factorial ANOVA test.

Regarding the qualitative analysis, the interviews were transcribed and exported into NVivo-11 software. The 'live categories' were identified and used for the coding process, then the relevant categories were identified from the matrix. Finally, a process of member checking was carried out to ensure inter-rater reliability, which consisted of the participants checking and approving the results (Johnson and Christensen 2012).

\section{Ethics}

The ethics committee of the research team's university and the educational board approved the conduct of the study. Additionally, the parents or guardians of the students signed an informed consent document. 


\section{Results}

This section is divided into two parts, the first explaining the quantitative results and the second for the qualitative results. Then, following the recommendations for mixed methods, both types of results are jointly addressed in the discussion section (Creswell and Plano Clark 2007).

\section{Results of the quantitative analysis}

The mixed ANOVA test showed significant effects for the group variable $(F(1,47)=23.38, p<.001$, $\eta^{2}=.332$ ). A significant effect can be seen on the teenagers belonging to the CLIL group ( $M=$ 982.09, SD =124.02), who did not fulfil the proposed hypothesis and spent significantly more time in the MVPA zone than the members of the NON-CLIL group $(M=815.80, S D=116.60)$.

However, the factorial ANOVA test showed a significant effect of the gender variable $(F(1,45)=$ $\left.6.48, p=.014, \eta^{2}=.126\right)$. As expected, the time spent in the MVPA zone was greater for boys $(M=$ $970.38, S D=169.13)$ than for girls $(M=853.20, S D=114.39)$. The group $x$ gender interaction for the MVPA zone did not reach statistical significance $\left(F(1,45)=0.18, p=.672, \eta^{2}=.004\right)$. However, it is worth noting that the mean time spent on MVPA for the girls in the CLIL group $(M=936.99, S D=$ 53.94) was higher than that of the boys in the NON-CLIL group $(M=869.89, S D=125.75)$. Table 2 shows the mean percentages of time that both groups spent at levels of MVPA throughout the unit.

\section{Results of the qualitative analysis}

The coding matrix indicated various categories, which were identified and then critically assessed by the research team. The intention of this process was to analyse which of the categories could explain the results obtained in the quantitative part of the study. The purpose of the critical analysis was, therefore, to study the different categories in order to elicit the reasons why the students in the experimental group (CLIL) had higher levels of MVPA. In this respect, 'student attention' and 'communicative teaching strategies' were the categories that answered the research question. The original excerpts and statements were in Spanish and have been translated into English by a professional translator for publication.

\section{Student attention}

With regard to the 'student attention' category, the evidence is based on the common discourse by the different interviewees. On the one hand, the teacher noticed an increase in the students' attention, 'I think they paid more attention', although she was cautious because this was her own opinion. However, this idea was endorsed by the students themselves, who said 'we had to pay a lot more attention, because before [if you didn't understand something] a friend would explain it to you and then you knew, but not now. We had to listen carefully to her [the teacher]' (El-1).

This is supported by comments such as 'in Spanish we wouldn't have paid as much attention and we would have completely missed the explanations' (EI-1) and

when she [the teacher] explained something, we were paying more attention than if it had been in Spanish, because otherwise we wouldn't have been able to play, but as it was in English you were concentrating on what she said and trying to understand it. (EG-7)

Table 2. Percentage of time per session spent on MVPA.

\begin{tabular}{lcc}
\hline & CLIL & NON-CLIL \\
\hline General & $(M=35.15, S D=4.49)$ & $(M=30.33, S D=4.33)$ \\
Boys & $(M=37.29, S D=5.95)$ & $(M=32.30, S D=4.73)$ \\
Girls & $(M=33.51, S D=1.92)$ & $(M=29.61, S D=4.06)$ \\
\hline
\end{tabular}

Note: $M=$ mean per session.

Source: Author's own data. 
In short, this idea is conveyed in the description given by the students, for whom the CLIL approach only involved 'wanting to pay more attention in order to understand everything. Otherwise it was the same' (El-4).

Moreover, from what the teacher said, it is also clear that the female students in particular showed more interest:

I have had female students who've volunteered several times to lead the warm-up, even though they found it hard to speak... The other day they volunteered too, and that shows they're interested in learning ... I've noticed that, despite finding it hard, the girls ... They wanted to take part. I don't know whether it's because they're interested in getting a higher mark or because they were motivated by learning (teacher).

Comments like this show that the girls were highly involved in this kind of lessons, suggesting that CLIL offered them a motivating challenge in PE. As seen in the previous section, this situation is entirely in accordance with the quantitative results of the study.

\section{Communicative teaching strategies}

With regard to the 'communicative teaching strategies' category, the teacher clearly stated that 'in this group I had to use different strategies'. In this respect, the students highlighted the use of non-verbal communication as a highly valuable tool to complement the teacher's explanations 'often she [the teacher] would say something and we would just stare because we didn't understand. So, she made a gesture and then we did it' (EG-4). This is clearly related to the previous category, since having to be attentive to both verbal and non-verbal communication means that the students are required to pay more attention in order to grasp information through the different channels used.

Another strategy identified referred to how the teacher adapted her language to ensure it was in line with the students' knowledge. This is conveyed by comments such as 'we understood because the vocabulary was adapted to suit us' (EI-3). The teacher also admitted to having had to prepare her speech more carefully and in greater detail in order to establish clearly 'what vocabulary I was going to use so that the students would be able to understand the vocabulary or structures in English'. As she herself pointed out, this is not taken into account to the same degree when giving classes in Spanish, as the students' understanding of the message is not impaired.

In short, the qualitative results showed that applying CLIL in PE brought about an increase in 'student attention', especially among girls, and led to the use of certain 'communicative teaching strategies' such as: (1) reinforcing the message through a complementary non-verbal communication channel, and (2) the teacher adapting the language she used to suit the students' level.

\section{Discussion}

The results yielded by the mixed methodological approach are complemented in order to address the concerns of the research. Through the combination of these two perspectives, the primary hypothesis was rejected, and it was possible to answer the research question considered in this study. The results of the study suggest that the levels of MVPA in the experimental group (CLIL) are higher due to an increase in the attention paid by the students and the use of communicative teaching strategies related to the application of CLIL. This theory is based on the statistical significance of the comparison of MVPA levels between the experimental group and the control group, and the observations made in the interviews. Bearing in mind that different authors have expressed concern that CLIL may have a negative effect on students' levels of physical activity in PE lessons (Coral 2013; Lynott 2008), it would be fair to say that the results of the study are at least promising.

In a pilot study, Coral et al. (2017) used an observation tool to measure the amount of physical activity in PE sessions with CLIL, concluding that the students spent less than the recommended time on motor activities, although they did not specify the intensity of the activity. Their study suggests that the reasons for this lack of activity may be attributed to excessive use of language learning materials or the type of physical activity proposed in CLIL sessions. However, with regard to the 
moderate-vigorous intensity that interests us in our study, the use of accelerometry has shown that the percentage of time that the students in the experimental group remained at levels of MVPA was $35.15 \%$, a similar figure to that of other research studies using this same measuring procedure. Therefore, if the levels of MVPA in the CLIL group are compared with those found in other studies on PE in NON-CLIL groups, it can be seen that the percentages are very similar. For example, Meyer et al. (2013) showed that primary school pupils spent $32.8 \%$ of their PE sessions at levels of MVPA. Ferreira, Mota, and Duarte (2014) found that teenage students remained at these levels of intensity for $28.18 \%$ of the sessions, while the research by Kremer, Reichert, and Hallal (2011) concluded that they remained at levels of MVPA for $32.7 \%$ of the class time.

Likewise, our results can be compared with those obtained in the meta-analysis by Hollis et al. (2017), which concluded that the studies where accelerometers were used as a measuring instrument showed that, on average, $34.7 \%$ of the PE session was spent at levels of MVPA, while in all the studies relating to secondary education, like our own, the students remained at those levels for $35.9 \%$ of the class time.

Regarding the comparison of the two groups participating in this study to verify the impact of CLIL, the results showed a statistically significant difference in the levels of MVPA in favour of the experimental group (CLIL). Based on the interviews, the greater attention paid by the students in that group is one possible explanation for these unexpected results. The introduction of English into PE might be directly connected to the students' paying more attention to the explanation given. This might in turn explain the increase in time spent on physical activities. Consequently, if the explanation time is optimised, and the time spent on activities is increased, it seems reasonable that the percentage of MVPA in the experimental group should have been greater than that of the control group due to the use of CLIL. This increase in attention is consistent with the findings of Baena, Gómez, and Granero (2017), who state that students participating in CLIL programmes were more motivated, or those of Fernández-Río, Hortigüela Alcalá, and Pérez Pueyo (2017), who found that the students who formed part of bilingual groups showed greater levels of responsibility.

Additionally, the teacher's use of communicative teaching strategies (verbal and body language) could offer another explanation for the greater time spent on MVPA by the students in the CLIL group. Adaptation of the language used (adjusted to suit the students' level of English) and more use of body language are two strategies that can make explanations shorter and more easily understood, as proposed by Gómez and Jiménez (2012), Gruber (2015) and Salvador and Chiva (2017). Exploring this matter in more depth, both Ting (2011) and Zindler (2013) established that teachers who apply CLIL are more careful about the vocabulary and language structures they use to ensure effective communication, restricting themselves to more basic communicative messages that require the students to listen more attentively. However, these actions contrast with the excessive use of language learning materials, which, according to the study by Coral et al. (2017), could lead to a decrease in physical activity.

Considering the levels of MVPA by gender, the boys achieved higher levels than the girls. These results are in line with those presented by Harvey et al. (2016), Kremer, Reichert, and Hallal (2011) and Meyer et al. (2013) in their respective research studies on levels of MVPA in PE. According to these studies, as a general rule, boys tend to be more active than girls in PE lessons. However, it is interesting to note that, in our design, if we compare the mean levels of MVPA for the boys and girls in each of the two groups, the girls in the CLIL group all showed similar levels of MVPA, with a higher average than the boys in the NON-CLIL group, although the differences are not statistically significant. This possible trend, which could be explored in further studies, may be explained by the fact that the students' motivations and attitudes to learning a foreign language differ according to gender (Clark 1995; Doiz et al., 2014), as the girls tend to be more engaged. In this regard, incorporating CLIL into lessons may provide a more motivating challenge for the girls (López Rúa 2006); therefore, its implementation within the context of PE could be a positive motivating factor for female students, indirectly leading to increased levels of MVPA. 
Finally, it is fair to say that, due to the sample size, it is not possible to make any strong generalisations. However, to counteract and/or minimise the effects of this limitation, it should be stressed that the study objectively measures the levels of MVPA of all the students involved, unlike most research using accelerometry, in which a smaller sample is measured.

\section{Conclusions}

This article has addressed a quandary encountered in PE when trying to meet the requirements of different educational bodies and institutions. On the one hand, the WHO states that PE must increase MVPA in order to promote healthy lifestyles. On the other, many educational authorities have firmly chosen this subject to implement multilingual plans through the use of CLIL. These requirements appear to be at odds with each other, given that placing the emphasis on learning a new language, with the consequent implications this has for the subject, could mean that the level of MVPA in classes would decrease. However, the results of our study showed that not only do levels of MVPA not decrease, but they actually increase with the application of CLIL. This situation is most likely due to an increase in the students' attention and the use of teaching strategies related to how the approach is put into practice. Despite suggesting favourable prospects for expanding the application of CLIL in PE, these results are still surprising and further research is therefore needed to verify and discuss them.

\section{Acknowledgements}

The authors thank the NIH Library Writing Center for manuscript editing assistance.

\section{Disclosure statement}

No potential conflict of interest was reported by the authors.

\section{Funding}

This work was supported by the UJI-PREDOC/2016/03.

\section{Notes on contributors}

Celina Salvador-García, PhD, MSed, in-service English teacher.

Oscar Chiva-Bartoll, PhD, MSed, assistant Professor in the Corporal Expression Area, specialised in Physical Education, Sport Management and Service-Learning.

Carlos Capella-Peris, PhD, MSed, postdoctoral IRTA Fellow, specialised in Physical Education, Service Learning and Social Entrepreneurship.

\section{ORCID}

Celina Salvador-García (D) http://orcid.org/0000-0003-0776-8760

Oscar Chiva-Bartoll (iD http://orcid.org/0000-0001-7128-3560

Carlos Capella-Peris (D) http://orcid.org/0000-0003-2520-0650

\section{References}

Baena, A., M. Gómez, and A. Granero. 2017. "Aprendizaje de la educación física bilingüe a partir de las metas de logro y el clima de aprendizaje." Porta Linguarum 28: 81-93.

Calahorro, F., G. Torres-Luque, I. López-Fernández, A. Santos-Lozano, N. Garatachea, and E. Álvarez. 2015. “Actividad física y acelerometría; orientaciones metodológicas, recomendaciones y patrones." Nutrición Hospitalaria 31 (1): $115-128$. doi:10.3305/nh.2015.31.1.7450. 
Cenoz, J., F. Genesee, and D. Gorter. 2014. "Critical Analysis of CLIL: Taking Stock and Looking Forward." Applied Linguistics 35 (3): 243-262. doi:10.1093/applin/amt011.

Chiva, Ò., and C. Salvador. 2016. Aprendizaje integrado de educación física y lengua Inglesa. Barcelona: INDE.

Clark, A. 1995. "Boys into Modern Languages: An Investigation of the Discrepancy in Attitudes and Performance between Boys and Girls in Modern Languages." Gender and Education 7 (3): 315-326.

Coral, J. 2013. "Physical Education and English Integrated Learning: How School Teachers can Develop PE-in-CLIL Programmes." Temps d'Educació 45: 41-64.

Coral, J., M. Urbiola, E. Sabaté, J. Bofill, T. Lleixà, and R. Vilà. 2017. "Does the Teaching of Physical Education in a Foreign Language Jeopardise Children's Physical Activity Time? A Pilot Study." International Journal of Bilingual Education and Bilingualism, 1-16. doi:10.1080/13670050.2017.1407289.

Coyle, D. 2010. "Foreword." In CLIL in Spain: Implementation, Results and Teacher Training, edited by D. Lasagabaster, and Y. Ruiz de Zarobe, vii-viii. Newcastle upon Tyne: Cambridge Scholars Publishing.

Coyle, D. 2015. "Strengthening Integrated Learning: Towards a New Era for Pluriliteracies and Intercultural Learning." Latin American Journal of Content and Language Integrated Learning 8 (2): 84-103. doi:10. 5294/laclil.2015.8.2.2.

Coyle, D., P. Hood, and D. Marsh. 2010. CLIL. Cambridge: CUP.

Creswell, J. W., and V. L. Plano Clark. 2007. Designing and Conducting Mixed Methods Research. Thousand Oaks, CA: Sage Publications.

Creswell, J. W., V. L. Plano Clark, M. L. Gutmann, and W. E. Hanson. 2003. "Advanced Mixed Methods Research Designs." In Handbook of Mixed Methods in Social and Behavioral Research, edited by A. Tashakkori, and C. Teddlie, $209-240$. Thousand Oaks, CA: Sage.

Dalton-Puffer, C. 2011. "Content-and-Language Integrated Learning: From Practice to Principles?" Annual Review of Applied Linguistics 31 (2): 182-204. doi:10.1017/S0267190511000092.

Fairclough, S., and G. Stratton. 2005. "Physical Activity Levels in Middle and High School Physical Education: A Review." Pediatric Exercise Science 17 (3): 217-236.

Fernández-Río, J., D. Hortigüela Alcalá, and Á. Pérez Pueyo. 2017. “Educación bilingüe, streaming y metas sociales en estudiantes de secundaria." Revista de Educación 377: 30-53. doi:10.4438/1988-592X-RE-2017-377-352.

Ferreira, F. S., J. Mota, and J. A. Duarte. 2014. "Patterns of Physical Activity in Portuguese Adolescents. Evaluation During Physical Education Classes through Accelerometry." Archives of Exercise in Health and Disease 4 (2): 280-285. doi:10. 5628/aehd.v4i2.135.

Flick, U. 2009. An Introduction to Qualitative Research. London: SAGE.

Forey, G., and L. M. E. Cheung. 2019. "The Benefits of Explicit Teaching of Language for Curriculum Learning in the Physical Education Classroom." English for Specific Purposes 54: 91-109. doi:10.1016/j.esp.2019.01.001.

Ginciene, G., and S. Q. Matthiesen. 2017. "The Sport Education Model on the Teaching of Track and Field in School." Movimento 23 (2): 729-742.

Gómez, C. L., and M. Jiménez. 2012. "The Physical Educator as a Language Teacher for English Language Learners." Strategies 25 (4): 14-17. doi:10.1080/08924562.2012.10592157.

Griva, E., and K. Kasvikis. 2015. “CLIL in Primary Education: Possibilities and Challenges for Developing L2/FL Skills, History Understanding and Cultural Awareness." In Current Trends and Issues in Higher Education: An International Dialogue, edited by N. Bakić-Mirić, and D. Erkinovich-Gaipov, 101-124. Cambridge: Cambridge Scholars.

Gruber, K. 2015. "Improving Students' Foreign Language Competence through Content and Language Integrated Learning (CLIL) in Physical Education." Doctoral thesis, Wien University.

Harvey, S., M. L. Smith, Y. Song, D. Robertson, R. Brown, and L. R. Smith. 2016. "Gender and School-Level Differences in Students' Moderate and Vigorous Physical Activity Levels When Taught Basketball through the Tactical Games Model." Journal of Teaching in Physical Education 35 (4): 349-357. doi:10.1123/jtpe.2016-0089.

Hollis, J. L., R. Sutherland, A. J. Williams, E. Campbell, N. Nathan, and L. Wolfenden. 2017. "A Systematic Review and MetaAnalysis of Moderate-to-Vigorous Physical-Activity Levels in Secondary School Physical Education Lessons." International Journal of Behavioral Nutrition and Physical Activity 14 (1): 52. doi:10.1186/s12966-017-0504-0.

Johnson, B., and L. Christensen. 2012. Educational Research. Quantitative, Qualitative and Mixed Approaches. Thousand Oaks, CA: Sage.

Kremer, M. M., F. F. Reichert, and P. C. Hallal. 2011. "Intensity and Duration of Physical Efforts in Physical Education Classes." Revista de Saúde Pública 46 (2): 320-326.

López Rúa, P. 2006. "The Sex Variable in Foreign Language Learning: An Integrative Approach." Porta Linguarum 6: $99-114$. Lynott, F. J. 2008. "Integrating Other Subject Matter without Jeopardizing Physical Education Goals: The Content Linkage Approach." Strategies 22 (1): 10-17.

Marsh, D. 2012. Content and Language Integrated (CLIL): A Development Trajectory. Córdoba: Servicio de publicaciones de la Universidad de Córdoba.

Martínez, J. M., O. R. Contreras, S. Aznar, and A. Lera. 2012. "Niveles de actividad física medido con acelerómetro en alumnos de $3^{\circ}$ ciclo de educación primaria: actividad física diaria y sesiones de educación física." Revista de Psicología del Deporte 21 (1): 117-123.

Martínez, F. J., and E. García. 2017. "Influencia del bilingüismo en el tiempo de compromiso motor en educación física." Retos. Nuevas Tendencias en Educación Física, Deporte y Recreación 32: 178-182. 
McKenzie, T. L., S. J. Marshall, J. F. Sallis, and T. L. Conway. 2000. "Student Activity Levels, Lesson Context, and Teacher Behavior During Middle School Physical Education." Research Quarterly for Exercise and Sport 71 (3): 249-259.

Mehisto, P., D. Marsh, and M. J. Frigols. 2008. Uncovering CLIL Content and Language Integrated Learning in Bilingual and Multilingual Education. Oxford: Macmillan.

Merino, J. 2016. "Non-Linguistic Content in CLIL: Is Its Learning Diminished?" In CLIL Experiences in Secondary and Tertiary Education: In Search of Good Practices, edited by D. Lasagabaster, and A. Doiz, 17-43. Bern: Peter Lang.

Merino, J. A., and D. Lasagabaster. 2018. "The Effect of Content and Language Integrated Learning Programmes' Intensity on English Proficiency: A Longitudinal Study." International Journal of Applied Linguistics 28 (1): 18-30. doi:10.1111/ijal. 12177.

Meyer, U., R. Roth, L. Zahner, M. Gerber, J. J. Puder, H. Hebestreit, and S. Kriemler. 2013. "Contribution of Physical Education to Overall Physical Activity." Scandinavian Journal of Medicine \& Science in Sports 23 (5): 600-606. doi:10. 1111/j.1600-0838.2011.01425.x.

Murillo, B., J. A. Julián, L. García-González, A. Abarca-Sos, and J. Zaragoza. 2014. "Influencia del género y de los contenidos sobre la actividad física y la percepción de competencia en educación física." Revista Internacional de Ciencias del Deporte 10 (36): 131-143.

Patton, M. Q. 2002. Qualitative Research and Evaluation Methods. London: Sage.

Pérez-Cañado, M. L. 2016. "Stopping the 'Pendulum Effect' in CLIL Research: Finding the Balance between Pollyanna and Scrooge." Applied Linguistics Review 8 (1): 79-99. doi:10.1515/applirev-2016-2001.

Rowlands, A. V., K. Rennie, R. Kozarski, R. M. Stanley, R. G. Eston, and T. S. Olds. 2014. "Children's Physical Activity Assessed with Wrist- and Hip-Worn Accelerometers." Medicine and Science in Sports and Exercise 46 (12): 2308-2316.

Salvador, C., and Ò. Chiva. 2017. "CLIL in Teaching Physical Education: Views of the Teachers in the Spanish Context." Journal of Physical Education and Sport 17 (3): 1130-1138. doi:10.7752/jpes.2017.03174.

Salvador, C., Ò. Chiva, and E. Isidori. 2017. "Aprendizaje de una lengua extranjera a través de la educación física: una revisión sistemática." Movimento 23 (2): 647-660.

Tejedor, F. J. T. 2000. “El diseño en la evaluación de programas." Revista de Investigación Educativa 18 (2): 319 -339.

Ting, Y. T. 2011. "CLIL ... Not Only Not Immersion but Also More Than the Sum of Its Parts." ELT Journal 65 (3): $314-317$.

US Department of Health and Human Services. 2012. Physical Activity Guidelines for Americans Midcourse Report. Washington, DC: US Department of Health and Human Services.

WHO (World Health Organization). 2013. Global Action Plan for the Prevention and Control of Noncommunicable Diseases 2013-2020. http://www.who.int/mediacentre/factsheets/fs385/es/.

Zindler, K. 2013. "Content and Language Integrated Learning (CLIL) and PE in England. An Exploratory Study." Doctoral thesis, University of Sheffield, Sheffield. 